\title{
Efficiëntie versus illusies: maakt dat het verschil bij het gevangenisbeleid in de Lage Landen?
}

\author{
René van Swaaningen \\ Professor, Erasmus School of Law, Criminology, \\ Erasmus University of Rotterdam
}

Wanneer mensen met wie je hebt samengewerkt met emeritaat gaan, dan is je eerste gedachte: nu al? En ook onherroepelijk: heden gij, morgen ik... Degene die met emeritaat gaat denkt daar zelf wellicht anders over, maar ik blijf het een enigszins confronterend idee vinden. Voor mij blijft Sonja Snacken altijd de jonge vrouw die ik bijna dertig jaar geleden leerde kennen. Volgens mij hebben we elkaar op 18 juni 1992 leren kennen tijdens het afscheidssymposium voor Riekent Jongman aan de Rijksuniversiteit Groningen. Ik weet onder meer nog hoe komisch ik het vond dat Kristel Beyens en Sonja Snacken toen naar hun toenmalige vakgroepsvoorzitter Chris Eliaerts verwezen als 'den baas'; later begreep ik dat dat vooral een uiting van bijzonder aimabele onderlinge verstandhoudingen was.

Tussen ons twee klikte het direct goed. We werkten op gelijkaardige thema's - gevangeniswezen en penale politiek in bredere zin - en daar hadden we ook nog vergelijkbare ideeën over. Soms zagen we elkaar op de VUB, maar meestal ergens anders in Europa: op een symposium in België of Nederland, op een werkgroep van de Groupe Européen de Recherche sur les Normativités (GERN) of een interlabo van het tijdschrift Déviance et Société of op een congres van de European Society of Criminology (ESC). Over het algemeen ben ik geen liefhebber van openingsceremonies van dergelijke congressen, waar een heel bataljon aan politieke, politiële en justitiële gezagsdragers komt vertellen hoe ongelofelijk belangrijk het betreffende congres wel is, maar toen Sonja Snacken in 2015 in Porto de oeuvreprijs van de ESC kreeg, wilde ik daar wel graag bij zijn om te delen in de feestvreugde. ${ }^{1}$

1 https://www.vub.be/nieuws/2015/06/16/professor-sonja-snacken-wint-2015-esceuropean-criminology-award 
In 2011 zijn Sonja en ik samen geïnterviewd voor Knack. Het thema van dit dubbelinterview was: 'België-Holland achter de tralies: efficiëntie versus illusies' (Van Daele, 2011). Daar zou ik in dit liber amicorum graag nog eens op reflecteren. De titel van mijn bijdrage is ook aan dit interview ontleend. Heel kort samengevat is de lijn van het stuk dat er in het Belgische gevangenisbeleid penologisch beter doordachte beginselen leidend zijn en er vromere voornemens worden geformuleerd, maar dat de realisering daarvan in de praktijk nogal eens tegen valt, terwijl het Nederlandse detentiebeleid van de jaren negentig in illusielozere termen is gevoerd, waarbij 'streng en sober' het devies was, terwijl hier in de uitvoering de soep zelden zo heet werd gegeten als hij werd opgediend. De vraag die ik in deze bijdrage wil stellen is of dat toen eigenlijk wel klopte en of anno 2020 dan nog steeds zo is.

Het reductionisme, het bewust willen terugdringen van de vrijheidsstraf, neemt in het Belgische denken over straffen waarschijnlijk nog een belangrijkere plaats in dan in Nederland. Het streven naar een goede re-integratie van gedetineerden in de samenleving speelt hierbij een centrale rol. In het interview in de Knack zegt Sonja Snacken: 'Ik koester de Belgische illusies over reintegratie. Anders beland je in een onmenselijk, Amerikaans systeem: sluit ze op en gooi de sleutel weg.' Het woord 'illusie' duidt er al op dat die re-integratie niet altijd wordt gerealiseerd, maar dat neemt de waarde van het beginsel als zodanig natuurlijk niet weg. Hoewel ik nog altijd staande houd dat het Nederlandse detentiebeleid vanaf halverwege de jaren 1980 illusielozer is geworden, is het zeker niet zo dat daarmee het streven naar resocialisatie in Nederland is verdwenen. In lijn met analyses van Stanley Cohen over de 'punitive city' of van Clifford Shearing en Philip Stenning over de 'Disney Order of Social Control' is in Nederland echter sterker ingezet op 'nudging', het mensen een zetje in de goede richting geven, door middel van sanctiemodaliteiten buiten de gevangenis, en wordt resocialisatie binnen een detentie-setting vooral toegepast op de meest 'kansrijk' geachte categorieën delict plegers, terwijl sociaalzwakke plegers van delicten ervan worden uitgesloten (Boone, 2012).

Juist Nederland heeft vanaf 1953, toen de Beginselenwet gevangeniswezen werd ingevoerd een sterk op resocialisatie geënt detentiebeleid gevoerd, waarin ook een reductionistische agenda domineerde. En we kennen in Nederland natuurlijk ook een aantal voorbeelden van strafrechtcritici die relatief veel invloed hebben gehad op het justitiële beleid van de jaren 1960 tot 80: of het nu gaat om de Utrechtse School, om Hans Tulkens of om Louk Hulsman. Wij missen dit soort geluiden. Achteraf bezien meende Hulsman dat de in haar tijd zeer invloedrijk geachte - en mede door hem opgerichte - Coornhert Liga op de langere termijn nauwelijks een verbeterende invloed op de strafrechtspraktijk heeft gehad (Blad, 2012: 17). In dit licht heeft Stan 
Cohen er terecht op gehamerd dat het ondanks onze 'intellectuele scepsis' zinvoller is om onze eigen idealen en waarden voorzichtig te blijven benadrukken dan om een teleurgestelde cynicus te worden. Sonja Snacken haar werk - en persoon - kennende moet dit haar uit het hart zijn gegrepen. John Blad (2012) pleitte daarom ook voor de oprichting van een 'Hulsman-Liga'. In een in bredere kring levende onvrede met het huidige Nederlandse sanctiebeleid meende hij een draagvlak voor een dergelijke nieuwe vereniging voor strafrechtshervorming te ontwaren. Of die nieuwe liga er komt, is de vraag, maar er zijn in ieder geval plannen van een jongere generatie 'activisten' binnen Rescaled, dat streeft naar kleinschalige detentiefaciliteiten, om te bekijken wat we van de ervaringen van de Coornhert Liga kunnen leren. ${ }^{2}$

In het interview in de Knack betuigt Sonja Snacken zich een groot voorstander van dergelijke kleinschalige en lokale initiatieven. De politieke tendens in Nederland is helaas precies omgekeerd: er zijn vooral hele grote gevangenissen gebouwd (Lelystad, Zaanstad), waar automatisering een centrale plaats in de regimevoering inneemt. Daar bovenop is om intern politieke redenen besloten om in Vlissingen een nieuwe, grote extra beveiligde inrichting te bouwen, terwijl de bestaande extra beveiligde inrichting in Vught nog nooit geheel bezet is geweest en er legio gevangenissen door het hele land leegstaan. Oud-gevangenisdirecteur Frans Douw (2020) zegt hierover: 'Natuurlijk is er wel een verband met het functioneren van de andere gevangenissen. Als daar een groot personeelsgebrek is en de repressie en spanning neemt toe, dan creëer je zelf meer behoefte aan beveiligde plekken.' De perifere ligging van Vlissingen wordt ook terecht als een probleem gezien, maar ten tijde van de COVID-19-crisis zijn we geconfronteerd met bezoekproblemen in detentie- en asielzoekerscentra die we ons niet hadden kunnen voorstellen. ${ }^{3}$

Het is nog niet vaak opgemerkt, maar ik vind het een interessant gegeven dat er in Nederland al een vrij lange traditie is om gevangenissen die worden gesloten een andere bestemming te geven. Zo is in de jaren 1980

2 Rescaled is een Europees netwerk, waarin activisten en wetenschappers uit België, Nederland, Frankrijk, Portugal en Noorwegen zich buigen over initiatieven voor toekomstgerichte, kleinschalige detentieprojecten. Zie: https://www.rescaled.org/ In België heeft de VUB, en dan met name Kristel Beyens, een belangrijke rol in Rescaled gespeeld. In Nederland is het gelieerd aan Restorative Justice. Zie: http:// www.restorativejustice.nl/nl/projecten-activiteiten/rescaled/ Nationaal coördinator Veronique Aicha Archaoui heeft het initiatief genomen tot het 'afstoffen' van de ervaringen van de Coornhert Liga.

3 Mijn collega aan de EUR, Gwen van Eijk, heeft daar in haar columns een aantal schrijnende voorbeelden van laten zien. Zie: https://www.crimeur.nl/the-coronacrisis-inprisons-release-risk-and-human-rights/ 
het Huis van Bewaring aan de Amsterdamse Weteringschans omgebouwd tot een kantorencomplex, waarbij het kabinet van de rechter-commissaris werd omgetoverd tot debatcentrum De Balie en de luchtplaats tot het huidige Max Euweplein. ${ }^{4}$ Nadat na 2005 oude bajesen in respectievelijk Tilburg en Veenhuizen zijn verhuurd aan de Belgische en Noorse regering, of zijn omgekat tot asielopvang, zijn zij tegen 2020 (gedeeltelijk) gesloopt en tot woonwijk omgebouwd (de Amsterdamse Bijlmerbajes), tot hotel omgebouwd, waarbij de bajesstructuur nog duidelijk zichtbaar is (bijvoorbeeld in Almelo, Hoorn of Roermond) of omgebouwd tot een internationale school (in het voormalige Huis van Bewaring aan de Amsterdamse Havenstraat). Of dat in andere landen, bijvoorbeeld België ook (op deze schaal) gebeurt weet ik niet, maar het zou een aardig project zijn voor een student architectuur of criminologie om dat eens uit te zoeken.

De ontwikkeling van een herstelrecht heeft in België meer ingang gevonden dan in Nederland. Ik denk dat dit mede te danken is aan de niet aflatende inzet van Lode Walgrave en 'zijn' team van Leuvense criminologen. Natuurlijk kennen wij in Nederland de 'mediation' in strafzaken en de herstelgerichte detentie, en zelfs wordt de 'oer-term' voor herstelgericht werken, 'dading' nog steeds gehanteerd, maar ik durf toch te beweren, dat dit herstelgericht werken in Nederland alleen wordt 'getolereerd' binnen een strafrechtelijke setting en niet in plaats daarvan komt. De 'moeder' van het eerste dading-project in Nederland, Jacqueline de Savornin Lohman, heeft in een interview in het Tijdschrift over Cultuur \& Criminaliteit zelfs gesteld dat Justitie 'dading' om zeep heeft geholpen. Maar, in lijn met Stan Cohen's pleidooi, is de Savornin Lohman niet alleen maar pessimistisch, want, zo zegt zij poëtisch: 'er zijn steeds nieuwe mensen, die een betere wereld wensen' (van Swaaningen, 2016).

Toch kunnen we niet ontsnappen aan een zekere moedeloosheid als we kijken naar alle initiatieven om het strafrecht een stukje beter, humaner te maken die al zijn ontplooid en weer ter ziele zijn gegaan. Ooit was Justitie in de Buurt (JiB) bijvoorbeeld bedoeld als een laagdrempelige aanwezigheid van het Openbaar Ministerie in probleemwijken, die samenwerking op buurtniveau tussen diverse welzijnsinstellingen, de Raad voor de Kinderbescherming, Slachtofferhulp, scholen, kerken en moskeeën en bewoners zou moeten stimuleren en daarbij waar mogelijk herstelgericht zou werken. Geleidelijk aan werd de taak van de JiBs echter veel beperkter opgevat: zij moesten er

4 In een blog ben ik kort ingegaan op mijn persoonlijke ervaring met deze omvorming, die vrij bepalend is geweest voor mijn vorming als kritisch criminoloog: http://www. crimeur.nl/de-criminologische-relevantie-van-vijftig-jaar-paradiso/ 
uiteindelijk vooral voor zorgen dat er minder zaken voor de rechter worden gebracht en van enige missie ten aanzien van buurtopbouw of herstelrecht is nauwelijks sprake meer. En dan worden in 2004 de zogenaamde 'Veiligheidshuizen' gepresenteerd als 'JiB nieuwe stijl'. En in 2020 is op Rotterdam Zuid vervolgens een pilot gestart met 'probleemoplossende rechtspraak' in zogenaamde wijkrechtbanken (Koolenbrander, 2020). Wie het verschil tussen al deze alternatieven ziet, mag het zeggen. Dat zou ik als iets typisch Nederlands willen betitelen: we voeren iets in als pilot, hollen het initiatief vervolgens van binnenuit, de pilot wordt geëvalueerd, en ongeacht het resultaat van de evaluatie is er geen geld voor continuering; een paar jaar later krijgt iemand weer een goed idee, dat weliswaar heel erg lijkt op iets wat een paar jaar eerder was ingevoerd en weer afgeschaft, maar dat weet niemand meer; er komt weer een pilot en het hele circus begint weer van voren af aan.

Hoewel woorden als 'buurt' of 'gemeenschap' nog veelvuldig worden gebruikt, zien we feitelijk een tendens waarin de politiek, politie en justitie afstand nemen van ideeën over integratie en buurtopbouw en eerder de verbanning van probleemjongeren uit buurten bepleiten dan integratie. Katherine Beckett en Steve Herbert (2010) zien de terugkeer van de verbanning van ongewenste personen uit het straatbeeld als de volgende stap na 'broken windows' en 'zero tolerance policing'. In criminologische zin zijn we als het ware van een pragmatische invulling van Hirschi's bindingentheorie uit de jaren 1980 in de jaren 1990 en 2000 opgeschoven naar een beleidstheorie die is geïnspireerd op Kelling en Coles' 'broken windows'-benadering - met een aantal aan de levensloopcriminologie ontleende, op risicoprofilering geënte, interventies.

Net als in veel andere landen is straf vanaf de jaren 1990 ook in Nederland niet langer een instrument dat primair wordt ingezet om resocialisatie te bewerkstelligen, maar wordt het eerder beschouwd als een middel om de samenleving te beschermen tegen gevaarlijke categorieën burgers. Criminaliteit wordt steeds minder gezien als een gevolg van deprivatie en steeds meer als een symbool - zo niet een oorzaak - van sociaal verval, dat vooral om die reden moet worden bestreden (Downes \& van Swaaningen, 2007). Resocialisatie wordt vaak weggezet als een relikwie uit de 'softe jaren zeventig', maar uit onderzoek blijkt dat straf zonder resocialisatieprogramma een averechts effect op de recidive heeft, waardoor dus ook weer nieuwe slachtoffers worden gemaakt. Als welzijnsinterventies blijken te 'werken', waarom zou je ze dan nalaten? Alleen maar omdat ze niet 'hard' genoeg zouden zijn?

Wie in repressie gelooft meent al snel dat gevangenisstraf de enige serieuze sanctie is. Maar criminologen zoals Sonja Snacken worden niet moe te blijven onderstrepen dat er aan detentie, en de korte vrijheidsstraf in het 
bijzonder, het onderwerp van haar proefschrift (Snacken, 1986), ook belangrijke nadelen kleven. Zo worden mensen in de bajes niet zelden voor het eerst verslaafd, leren zij er de kneepjes van het 'vak', ontwricht het juist de meest kwetsbare gezinnen (doordat vader 'vast' zit) en belemmert het stigma 'gedetineerde' de heropname in de burgermaatschappij na het uitzitten van de straf, waardoor hernieuwd contact met de 'foute vrienden' van vroeger vaak de enige optie is.

Ondanks de schrale politieke wind, zijn er ook lichtpuntjes. In Nederland zijn we vanaf 2005 na dertig jaar groei weer minder gaan straffen. ${ }^{5}$ Bovendien is de criminaliteit verder gedaald nadat de detentieratio vanaf 2005 afnam. Zelfs de onveiligheidsgevoelens zijn in deze periode sterker dan voorheen gedaald. Er zijn mensen die menen dat dit komt doordat we in de jaren daarvoor strenger zijn gaan straffen, maar een dergelijk eenvoudig causaal verband valt niet te leggen. In de dertig jaar dat de gevangenisbevolking jaar na jaar toenam is de criminaliteit grosso modo alleen maar gestegen. Ook is het van belang te benadrukken dat de criminaliteit in veel meer Westerse landen is gedaald, maar dat dat elders meestal niet gepaard is gegaan met dalende detentiecijfers. In mijn bijdrage aan een boek dat Sonja Snacken mede heeft geredigeerd, stel ik de vraag of dalende detentiecijfers impliceren dat we in Nederland ook minder punitief zijn geworden. Mijn antwoord is dat we deze daling vooral moeten zien in het licht van een voortschrijdend proces van bifurcation - i.e. de groeiende tweedeling in de wijze waarop straffen ten uitvoer worden gelegd: tussen 'gemotiveerden' en 'niet-gemotiveerden', tussen detentie en taakstraf, tussen straf en preventieve interventies - van een ware 'punitive city' vol gemeenschapsstraffen en -maatregelen en van het feit dat er in toenemende mate sprake is van 'prepressie', waarbij preventief bedoelde programma's steeds meer punitieve trekjes kregen (van Swaaningen, 2013). Het nieuwe veiligheidsbeleid is bovendien sterk georiënteerd op zogenaamde 'pre-criminele' gedragingen, waarmee gedrag wordt bedoeld dat geen strafbaar feit oplevert, maar volgens risicotaxaties wel kan leiden tot criminaliteit.

Een mooie illustratie van deze 'prepressieve' ontwikkeling biedt de ontwikkeling van elektronisch toezicht en taakstraffen. Zoals uit de hoofdstukken van respectievelijk Kristel Beyens en Dan Kaminski over België en van Jolande uit Beijerse en mijzelf over Nederland blijkt, heeft elektronisch toezicht in onze beide landen een behoorlijk andere ontwikkeling doorgemaakt,

$5 \mathrm{Al}$ is het aantal gedetineerden volgens het Centraal Bureau voor de Statistiek na 2017 wel weer licht gestegen: van 33.540 in 2017 naar 33.960 in 2019. Het is nog te vroeg om daar enige redenen voor aan te wijzen, maar kijkend naar de statistieken lijkt deze stijging vooral te maken te hebben met een toename van het aantal voorlopig gehechten en het aantal 'veelplegers'. 
waarbij het in Nederland vooral een bijkomende maatregel in het kader van een gemeenschapsstraf is en zelf niet als een 'echte' sanctie wordt gezien (Nellis et al., 2013). In deze tijden van corona kan ik het niet laten een parallel te trekken met alle overleg dat wij de afgelopen maanden hebben moeten voeren via Zoom of Teams. Vaak vroeg ik mij af waarom mij dit zoveel meer uitput dan een 'normale' vergadering. Een psycholoog (ik ben de naam vergeten) verklaarde dit door het feit dat je door middel van Zoom of Teams wel de illusie van werkelijk contact hebt, je ziet iemand immers, maar dit feitelijk toch niet hebt. In deze lijn doordenkend kon elektronisch toezicht wel eens als 'zwaar' worden ervaren, omdat het door de illusie van (relatieve) vrijheid des te confronterender is.

En waar de taakstraf in Nederland oorspronkelijk een spiegelend karakter had, waarmee werd beoogd een delinquent met zijn fouten te confronteren, kwam gaandeweg het accent steeds meer op de werkstraf te liggen; liefst uit te voeren met op vernedering gerichte hesjes waar op staat dat men 'werkt voor de samenleving' (De Bruyckere, 2011). Een werkmeester van een Amsterdamse werkplaats voor taakgestraften zegt hierover: 'Mensen willen gestraften vaak zien lijden, maar als het dwangarbeid wordt, krijg ik ze nooit zover dat ze hier een vijver graven of een vlot bouwen. En laten ze daar nou ook nog iets van opsteken: sommigen vinden na hun werkstraf een baan als hovenier' (Lamers, 2011). Criminologisch onderzoek geeft deze werkmeester gelijk: voor expressief straffen (het afgeven van een sterk punitief signaal) is geen empirische steun.

Dat het in de penologische wereld nergens halleluja is hoeven we Sonja Snacken niet te vertellen (Snacken \& Dumortier, 2011) en dat het in Nederland (nog) slechter zou gaan dan in België durf ik ook niet te beweren. Maar bovenal kan ik een bijdrage aan een liber amicorum voor Sonja Snacken niet in mineur eindigen. Bij alle pleidooien voor strenger straffen die wij de afgelopen decennia hoorden, wordt het uiteindelijke doel van sancties vaak over het hoofd gezien: hoe zorgen we ervoor dat iemand zijn schadelijke gedrag afleert en geen nieuwe slachtoffers maakt? Hiertoe moeten we vooral verstandiger interveniëren en gebruik maken van het beschikbare onderzoek over wat, hoe, waarom en bij wie precies werkt. Hieraan werken gaat gepaard met een flinke dosis idealisme. De manier waarop wij straffen hangt ook sterk samen met onze opvattingen over democratie, humaniteit, beschaving en het beperken van menselijk lijden. Net als beschaafde landen mensen niet martelen of doden, proberen zij ook andere buitenproportionele of vernederende straffen zoveel mogelijk te voorkomen. Als geen ander heeft Sonja Snacken zich ervoor ingespannen om deze waarden hoog te houden. Wat moeten we anders? Wat blijft er van onze samenleving over wanneer we onze idealen en humaniteit verliezen? 


\section{Referenties}

Beckett, K. \& Steve H. (2010). Banished: The new Social Control in Urban America. Oxford, New York: Oxford University Press.

Blad, J. (2012). Pleidooi voor een Hulsman-Liga. In: J. Claessen \& D. de Vocht (Eds.), Humaan strafwerk: Liber Amicorum Gerard de Jonge (pp. 17-34), Nijmegen: Wolf Legal Publishers .

Boone, M. (2012). Eigen boeven eerst. Insluiting en uitsluiting in de sanctietoepassing, inaugurele rede Rijksuniversiteit Groningen. Den Haag: Boom Juridische Uitgevers.

De Bruyckere, A. (2011). Geef toe dat vernedering het doel is van die hesjes, in: NRC Handelsblad 2 augustus 2011.

Douw, F. (2020). Heeft Nederland een nieuw Justitieel Complex nodig? 'Neen', in: de Bonjo, augustus 2020, p.14.

Downes, D. \& van Swaaningen, R. (2007). The Road to Dystopia? Changes in the Penal Climate of the Netherlands. In M. Tonry \& C. Bijleveld (Eds.), Crime and Justice in the Netherlands. Chicago: The University of Chicago Press (31-72).

Koolenbrander, N. (2020). Probleemoplossende rechtspraak: de wijkrechtbank op Zuid. Een kwalitatief onderzoek naar de rol van probleemoplossend recht in de pilot wijkrechtspraak in Rotterdam-Zuid. Masterscriptie criminologie, Erasmus Universiteit Rotterdam.

Lamers, M. (2011). 'Iedereen kan opnieuw beginnen', in: Het Parool PS 17 december 2011, pp.18-23.

Nellis, M., Beyens, K. and Kaminski, D. (Eds.). Electronically Monitored Punishment; international and critical perspectives. London: Routledge.

Snacken, S. (1986). De korte vrijheidsstraf. Een onderzoek naar de toepassing en effectiviteit. Antwerpen: Kluwer.

Snacken, S. \& Dumortier, E. (Eds.) (2011). Resisting Punitiveness in Europe? Welfare, Human Rights and Democracy. London: Routledge.

Swaaningen, R. van (2013). Reversing The Punitive Turn: The Case of the Netherlands. In T. Daems, S. Snacken \& D. Van Zyl Smit (Eds.), European penology? Oxford: Hart (339-360).

Swaaningen, R. van (2016). Ouwer-power in de strafrechtshervorming: Significant Other Jacqueline de Savornin Lohman, in: Tijdschrift over Cultuur \& Criminaliteit, 6 (3), 91-103. https://tijdschriften.boomcriminologie. nl/tijdschrift/tcc/2016/3/TCC_2211-9507_2016_006_003_006

Swaaningen, R. van \& John R., B. (Eds.) (2011). De ontmaskering van het strafrechtelijk discours: een bloemlezing uit het werk van Louk Hulsman. Den Haag: Boom Juridische Uitgevers.

Van Daele, I. (2011). België-Holland achter de tralies: efficiëntie versus illusies, dubbel-interview met Sonja Snacken, Knack Extra, 2 november (30-33). 